\title{
Cloning and expression of Corynebacterium diphtheriae toxin gene
}

\author{
N. Mohammadi', M. Bandehpour ${ }^{2,3}$, P. Pakzad' and B. Kazemi ${ }^{2,3 *}$ \\ ${ }^{1}$ Islamic Azad University, Tehran North branch, Iran. \\ ${ }^{2}$ Cellular and Molecular Biology Research Center, Shaheed Beheshti University of Medical Sciences, Tehran, Iran. \\ ${ }^{3}$ Biotechnology Department, Faculty of Medicine, Shaheed Beheshti University of Medical Sciences, Tehran, Iran.
}

Accepted 23 August, 2011

\begin{abstract}
Diphtheria is an acute bacterial disease caused by oxygenic strains of Corynebacteria. Fatality rate of this disease, between 5 and $10 \%$. In children under 5 years and adults, the fatality rate may be as much as $20 \%$. Outbreaks, although very rare, still occur worldwide, even in developed nations. Diphtheria toxin (DT) is the major virulence factor for these organisms. The aim of this study was cloning and expression diphtheria toxin gene to produce recombinant protein and application in next investigations. The bacterial DNA was extracted and amplification of diphtheria toxin gene was carried out with specific primers. This gene was cloned in $\mathrm{PTZ57R/T}$ vector and sub cloned into $\mathrm{pETDuet}-1$ expression vector then recombinant plasmid was transformed into BL21 of Escherichia coli strain and induced by IPTG. Diphtheria toxin gene was amplified successfully and cloned in pTZ57R. Recombinant plasmid was digested by restriction enzymes and released fragment (diphtheria toxin gene) sub cloned in pETDuet-1 expression vector and expressed protein was analysed in serological assay. In this study, the diphtheria toxin gene was cloned in pETDuet-1 expression vector and confirmed by sequencing and restriction analysis then recombinant plasmid was transformed in BL21 expression cell.
\end{abstract}

Key words: Diphteria, Corynebacterium diphtheriae toxin gene, recombinant protein, pETDuet-1.

\section{INTRODUCTION}

Dphtheria is a highly infectious disease caused by Corynebacterium diphtheriae, an aerobic, gram-positive, nonsporulating bacterium. Fatality rate of this disease is between 5 and $10 \%$. In children under 5 years and adults, the fatality rate may be as much as $20 \%$. Outbreaks, although very rare, still occur worldwide, even in developed nations (Todar, 2008). The disease is usually transmitted by droplet contact. This is an upper respiretory tract illness characterized by sore throat, low fever, and an adherent membrane (called a pseudomembrane) on the tonsils, pharynx, and nasal cavity. Diphtheria toxin produced by $C$. diphtheriae, can cause myocarditis, polyneuritis, and other systemic toxic effects. A milder form of diphtheria can be restricted to the skin. The

\footnotetext{
${ }^{*}$ Corresponding author. E-mail: bahram_14@yahoo.com or kazemi@sbmu.ac.ir. Tel: +9821 22439957. Fax: +98 21 22439956.
}

virulence factor of $C$. diphtheriae is diphtheria toxin (DT), a highly toxic protein expressed after infection by a specifictox+ corynebacteriophage (Bachran et al., 2007; Brooks et al., 2007). After treat-ment with trypsin and reducing agents, toxin (molecular weight $62 \mathrm{KDa}$ ) can be dissociated into two polypeptides, fragment $A(21,145$ $\mathrm{KDa}$ ) and fragment $\mathrm{B}$ (38 KDa) (DeLange et al., 1976; Drazin et al., 1971; Gill and Dinius, 1971). Fragment A, the amino-terminal region of the toxin molecule, is an enzyme that catalyzes transfer of the adenosine diphosphateribose (ADP-ribosylation) moiety from nicotinamide adenine dinucleotide to eukaryotic elongation factor 2 (EF-2), thereby inactivating EF-2 and inhibiting protein synthesis in eucaryotic cells, and caused cell death (Collier and Kandel, 1971; Gill and Pappenheimer, 1971; Honjo et al., 1968). Fragment B, the carboxy-terminal portion of the toxin molecule is essential for the binding of toxin to specific receptors on the plasma membrane of susceptible eucaryotic cells, consists of two separate protein folding domains; the R- 
domain that binds to the cell surface receptor and the Tdomain that can insert into membranes and mediate translocation of the A-fragment across the membrane (Naglich et al., 1992; Ittelson and Gill., 1973; Uchida et al., 1973). Diphtheria toxin bound to its receptor is endocytosed by clathrin-dependent endocytosis. When the toxin encounters the acidic $\mathrm{pH}$ in the endosomes, a conformational change occurs and a double helix in the T-domain inserts into the endosomal membrane. The membrane-inserted hairpin assists the A-fragment to translocate across the endosomal membrane, and after reduction of the disulfide bridge the A-fragment is released in the cytosol (Papini et al., 1993). The aim of this study was cloning and expression diphtheria toxin gene to produce recombinant protein and application in next investigations.

\section{MATERIALS AND METHODS}

\section{Bacterial DNA and plasmids}

C. diphtheriae DNA was giftt from Razi Vaccine and Serum Research Institute. The pETDuet-1 and pTZ57R plasmids were purchased from Novagen Company.

\section{Gene cloning}

A pair of primer was designed based on Diphtheria toxin gene sequence: forward and reverse $F$ - 5'GGA TCC ATG GGC GCT GAT GAT GTT G-3` R- 5`- GAA TTC TCA GCT TTT GAT TTC AAA AAA TAG CG-3` with EcoRI and BamHI restriction enzymes site at $5^{\prime}$ end of forward and reverse primers respectively. The DNA of $C$. diphtheriae was extracted and Diphtheria toxin gene was amplified via PCR reaction and PCR product was submitted to electrophoresis using $1 / 5 \%$ agarose gel, then stained by sybergreen and submitted for sequencing by dideoxy chain termination method. Amplified fragment was cloned in pTZ57R plasmid by T/A cloning as reported previously (Gaastra and Hansen., 1984). Contents of reaction were transfer into E. coli, Top10 strain competent cell (Hanahan, 1983). Then product of reacion was dispensed on LB (Luria-Bertani) agar plate containing ampicillin $(50 \mathrm{mg} / \mathrm{mL})$, Xgal $(20 \mathrm{mM})$ and IPTG $(200 \mathrm{mg} / \mathrm{ml})$. White colonies containing recombinant plasmid was selected and extracted (Feliciecello and Chinali., 1993). Released DNA (dt gene) was sub cloned in BamHI and EcoRl digested pETDuet-1 expression vector and digested by BamHI and EcoRI restriction enzymes.

The released fragment DNA ( $d t$ gene) was ligated into BamHI and EcoRI digested pETDuet-1 expression vector and Recombinant plasmid was confirmed by both spacific PCR and enzyme digestion methods.

\section{Gene expression}

The $E$. coli strain BL21 was transformed with recombinant plasmid and selected on LB agar containing $50 \mu \mathrm{g} / \mathrm{ml}$ of ampicillin and incubated at $37^{\circ} \mathrm{C}$ in a shaker at $200 \mathrm{rpm}$ overnight (Sorensen and Mortensen, 2005; Baneyx, 1999). The following day, the cultured bacteria was inoculated into $50 \mathrm{ml} \mathrm{X}$ medium (1.2\% bacto trypton, $2.4 \%$ yeast extract, $0.04 \%$ glycerol, $1 \% \mathrm{M} 9$ salts) (M9 salts contain: $6.4 \% \quad \mathrm{Na}_{2} \mathrm{H}_{2} \mathrm{O}_{4}-7 \mathrm{H}_{2} \mathrm{O}, \quad 1.5 \% \quad \mathrm{KH}_{2} \mathrm{PO}_{4}, \quad 0.025 \% \mathrm{Nacl}, \quad 0.05 \%$
$\mathrm{NH} 4 \mathrm{CL}$ ) and was allowed to grow at $37^{\circ} \mathrm{C}$ in a shaker at $200 \mathrm{rpm}$ for $2 \mathrm{~h}$. When the cultures were in logarithmic phase (at $O_{600}$ of 0.6 ), the porometor gene was induced for different hours with $1 \mathrm{mM}$ isopropyl $\beta$ - D-thiogalactopyranoside (IPTG). After induction, cells were lysed in $5 x$ sample buffer $(100 \mathrm{mM}$ Tris HCL Ph $8.20 \%$ glycerol, $4 \%$ SDS, $2 \%$ beta mercapto-ethanol, $0.2 \%$ bromophenol blue) and analyzed by $10 \%$ SDS-polyacrylamide gel (Baneyx, 1999; Smith, 1984a).The gel was stained by coomassie brilliant blue R- 250 (Smith, 1984b). Uninduced control culture was analyzed in parallel.

\section{Serological assay}

\section{Immuno diffusion}

Gel diffusion was done using induced lysate cells as antigen and horse anti toxin serum as antibody loaded on $1 \%$ agarose gel in phosphate buffered saline (PBS) and incubated over night at $37^{\circ} \mathrm{C}$ (Hudsun and Hay, 1998).

\section{Dot blot analysis}

Lysate-induced cells were blotted on nitrocellulose membrane. Nitrocellulose membrane blot was reacted by primary antibody (horse anti toxin serum) and then by secondary antibody (rabbit anti- horse lgG peroxidase conjugated), and subsequently detected by its substrate (Shewry and Fido, 1998).

\section{Western blot analysis}

Protein resolved by SDS-PAGE was electrophoretically transferred to a nitrocellulose membrane. The membran was incubated in TBS (Tris-Buffered Saline containing 3\% BSA (Bovine Serum Albumin) and then washed several times. Membrane was then incubated with a 1:200 dilution of primary antibody (horse anti toxin serum) in a shaker at $70 \mathrm{rpm}$ for $2 \mathrm{~h}$. Then washed several times by TBS and TBST (TBS-Tween 20) subsequently treated with a 1:200 dilution horseradish peroxidase (HRP) rabbit anti- horse IgG peroxidase conjugated in a shaker at $70 \mathrm{rpm}$ for $2 \mathrm{~h}$. Afterwards washing several times, the strips were visualized for color after development in $\mathrm{Di}$ Amino Benzidine/ $\mathrm{H}_{2} \mathrm{O}_{2}$ substrate solution for $15 \mathrm{~min}$ at room temperature. The reaction was stopped by washing four times in distilled water (Sambrook and Russell, 2001).

\section{RESULTS}

C. diphtheriae toxin gene was amplified from extracted DNA of bacteria by using specific forward and reversed primers. Figure 1 shows $1611 \mathrm{bp}$ as PCR product that it was electrophoresed on $1.5 \%$ agarose gel in parallel with 100 bp DNA ladder size marker.

The PCR product was ligated in PTZ57R T-vector and transformed into $E$. coli Top10 strain. Recombinant plasmid was extracted and digested with BamHI and EcoRl restriction enzymes (Figure 2). Also recombinant plasmid was confirmed by PCR with specific primers (Figure 3). Release DNA band was purified by DNA purification kit and subcloned in $B a m H I$ and EcoRl digested pETDuet- 1 expression vector Figure 4 shows supercoil no recombinant plasmid and digested recombinant plasmid. Confirmation of the plasmid was 


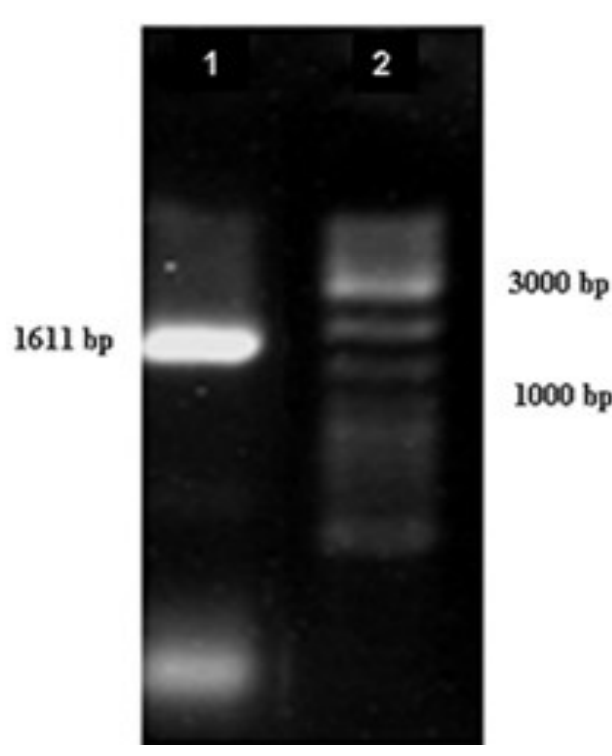

Figure 1. Electrophoresis of PCR on $1.5 \%$ agarose gel.

Line 1: The $1611 \mathrm{bp}$ as PCR product of $d t$ gene. Line 2: 100 bp DNA ladder marker.

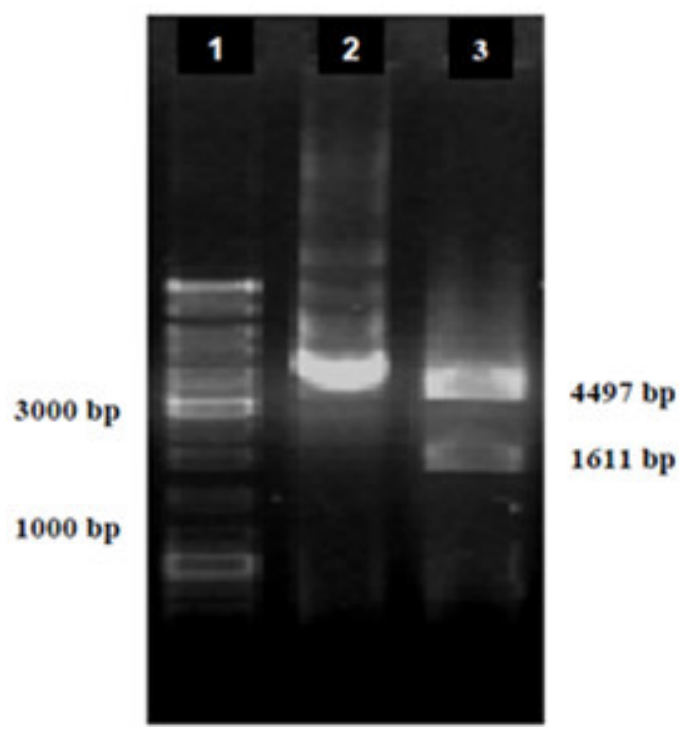

Figure 2. Electrophoresis on $1 \%$ agarose gel. Lane 1: 100 bp DNA ladder marker, Lane 2: not digested pTZ57R/dt, Lane 3: Digested pTZ57R/dt by BamHI \& EcoRI.

also showed by PCR (Figure 5).

Figure 6 shows SDS-polyacrylamide gel electrophoresis loaded by interval sampling 3 and 5 hours after induction by IPTG. The induced protein is approximately $60 \mathrm{kDa}$, parallel with the protein size marker.

Dot blot was used with $1 / 100,1 / 250,1 / 500$ diluted horse anti toxin serum as antibody and 1/200 diluted lysate induced cells as antigen. Figure 7 shows the dot

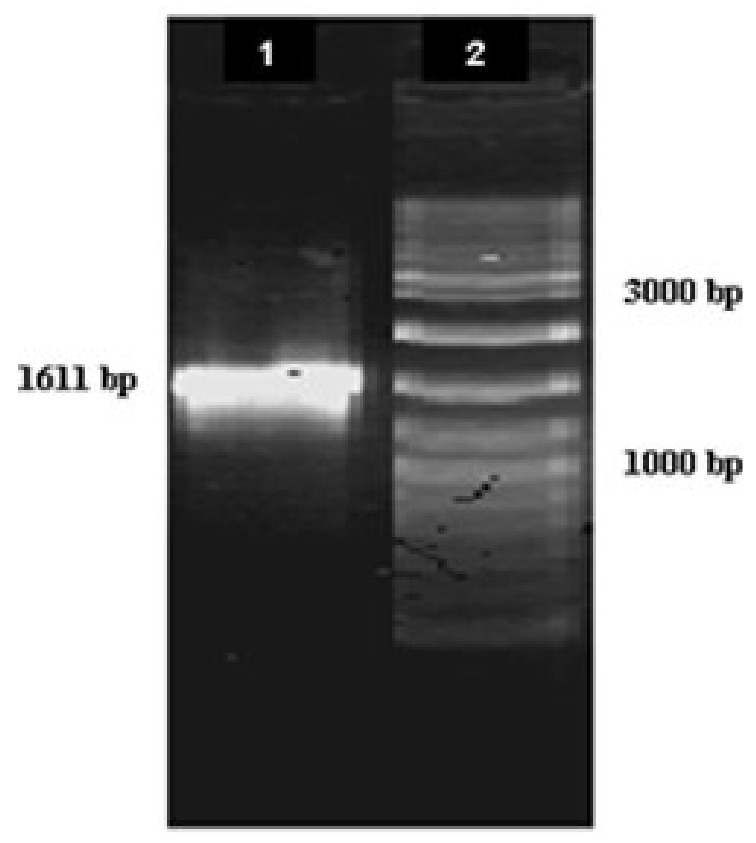

Figure 3. Electrophoresis of PCR on $1.5 \%$ agarose gel. Line 1: Confirming cloned gene in PTZ57R T/vector (using specific primer for $d t$ gene). Line 2: 100-bp DNA ladder marker.

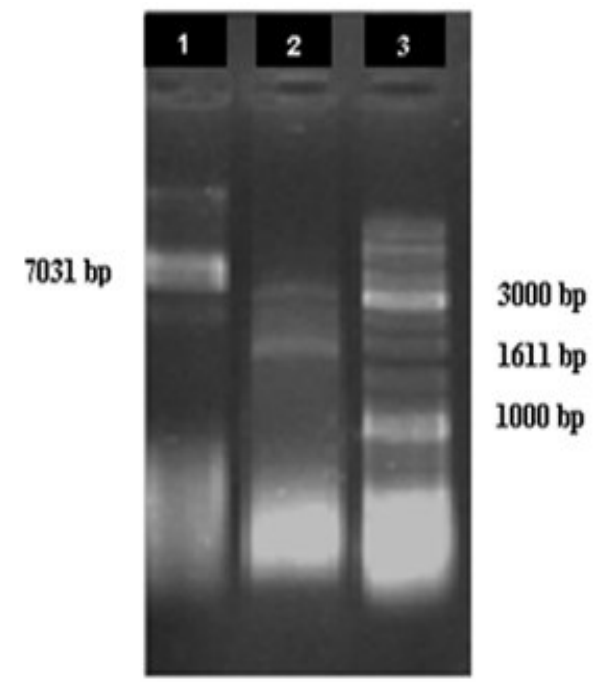

Figure 4. Electrophoresis on $1 \%$ agarose gel. Lane 1: not digested pETDuet-1/dt, Lane 2: Digested pETDuet-1/dt by BamHI\& EcoRI, Lane 3: 100 bp DNA ladder marker

blot analysis detected after the enzyme - substrate reaction.

Arc produced in gel diffusion test by antibody- antigen reaction, was seen using induced lysate cells as antigen and DT-infected serum as antibody (Figure 8).

Western blot analyse confirmed the protein with approximately $60 \mathrm{kDa}$ strip as recombinant protein that 


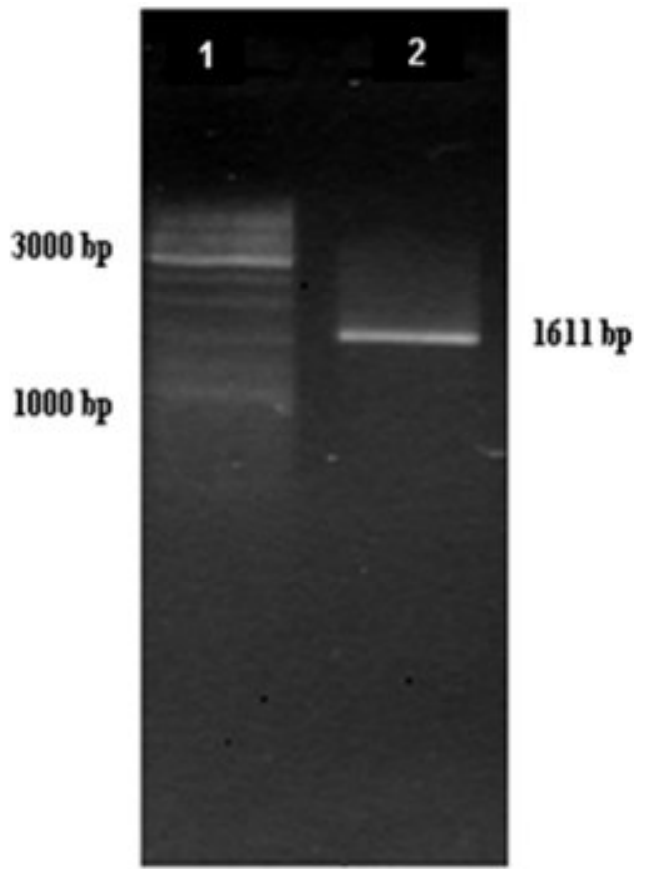

Figure 5. Electrophoresis of PCR on $1.5 \%$ agarose gel.

Line 1: 100 bp DNA ladder marker. Line 2: Confirming sub cloning $d t$ gene in pETDuet-1, expression vector (using specific primer for $\mathrm{dt}$ gene).

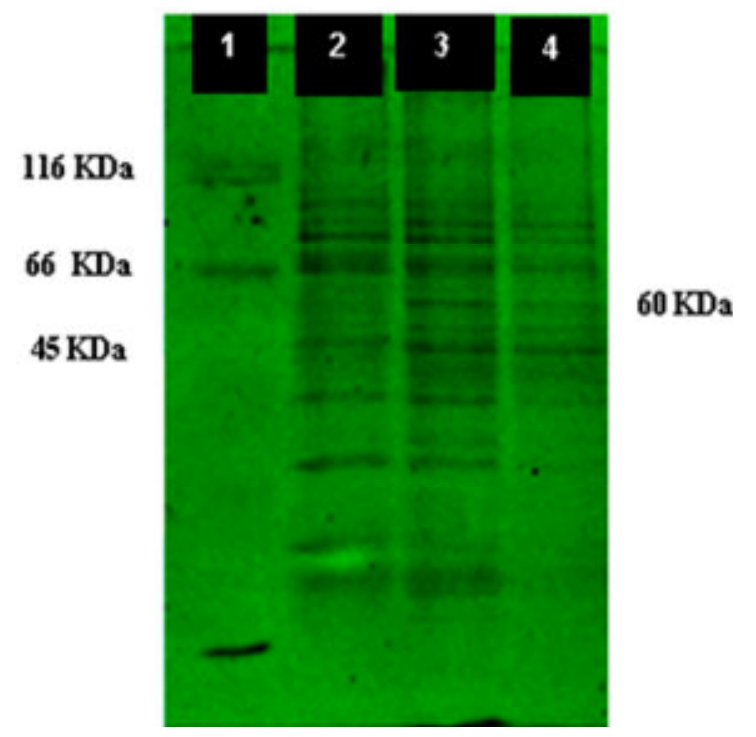

Figure 6. SDS-polyacrylamide gel electro-phoresis. Line 1: protein marker. Line 2: Lysate of BL21 cell without recombinant DT protein. Line 3: Lysate of BL21 containing recombinant DT protein, collected $3 \mathrm{~h}$ after induction. Line 4: Lysate of BL21 containing recombinant DT collected $5 \mathrm{~h}$ after induction.

was transferred to nitrocellulose membrane (Figure 9).

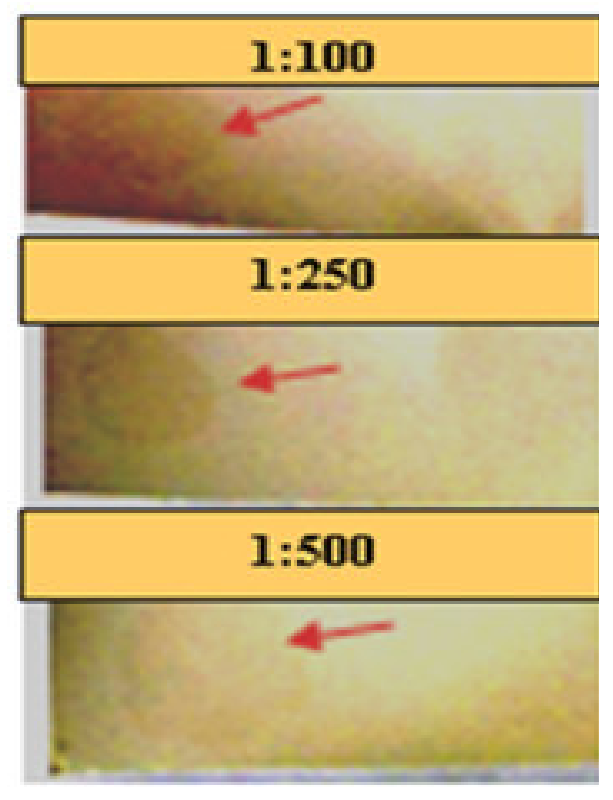

Figure 7. Dot blot analysis by $1: 100,1: 250$ and 1:500 diluted DT-anti toxin serum and detected by rabbit anti- horse IgG peroxidase conjugated.

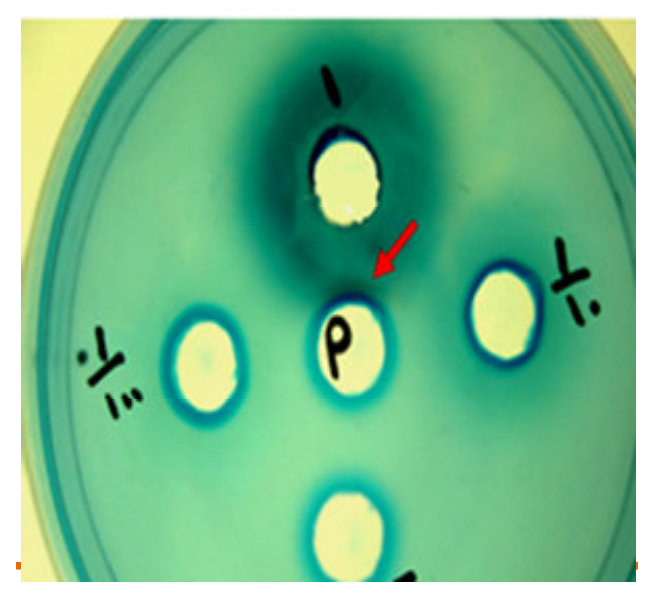

Figure 8. Immuno diffiusion analysis by 1, 1:10 and 1:100 diluted DT anti toxin serum, p: Lysate of BL21 containing recombinant DT, collected 3 $\mathrm{h}$ after induction s: negative serum.

1 2

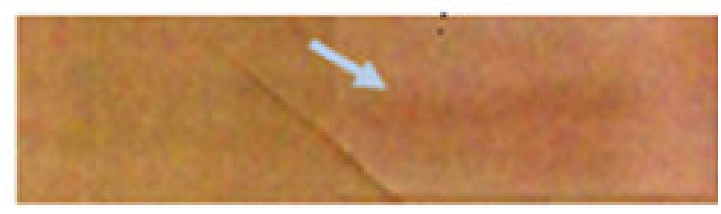

Figure 9. Immunoblotting.

Line 1: Cell lysates without recombinant DT, Line 2: Cell lysates containing recombinantt DT $3 \mathrm{~h}$ after induction (expression). 


\section{DISCUSSION}

Diphtheria was one of the most important causes of death in the first half of the twentieth century (Skogen et al., 2000). The exotoxin of toxigenic strains of C. diphtheriae is responsible for local and systemic toxicity seen during diphtheria (Mandell and Dolin, 1995). Immunity to diphtheria is mainly provided by IgG antibodyies made against the exotoxin, which is a powerful antigen (Bigio et al., 1987). Some epidemiological studies were carried out by this antigen (Holmes, 2000) and some studies were used this antigen for vaccination (Lobeck et al., 1998). Others used this antigen for diagnosic (Aybay and Yücel., 2003 Nakao and Popovic, 1997; Mikhailovich et al., 1995). In 1909, Smith proposed that nontoxic mixtures of DT and diphtheria antitoxin at equivalence could be used for active immunization of humans against diphtheria. A successful large-scale trial of toxin-antitoxin vaccine was conducted in 1922. Ramon in 1923 discovered that treatment with formalin eliminated the toxicity of DT without destroying its immunogenicity. Formalin-treated DT, now called diphtheria toxoid, Diphtheria toxoid usually in combined vaccines, such as diphtheria-tetanus toxoids- pertussis vaccine [DTP] or diphtheria-tetanus toxoids-acellular pertussis vaccine [DTaP] for children and tetanusdiphtheria, toxoids vaccine for adults [Td]) is still used throughout the world for active immunization against diphtheria (Holmes., 2000). Nowadays diphtheria vaccine, require multiple doses to achieve protection, which has led to reduced coverage of imunization, also it may have some side effects in children, such as an allergic reaction (hives or a rash develops within minutes of the injection), seizures or shock - complications, furthermore Toxoids have traditionally been prepared by chemical modification of native toxins (http://www.cdc.gov/vaccines/vpdvac/diphtheria/default.htm) with formaldehyde, for example, the compound is known to be mutagenic and carcinogenic (Turosk, 1985). But molecularly cloned toxin genes now provide alternative genetic approaches to detoxification. Recombinant protein produced technology including the production of proteins which can not be readily purified from natural sources and the development of a small and selected number of amino acid substitutions to detoxify the original proteins, have been thus introduced (Barbieri et al., 1992; Beachey et al., 1981; Fromen-Romano et al., 1997). Besides having the potential to replace classical toxoids, recombinant toxoids could be incorporated by genetic engineering into live attenuated bacterial or viral vaccines currently being developed. Such live vaccines offer the possibility to immunize against a broad array of diseases by administering only a single dose of the vaccine (Killeen et al., 1992). Thus several studies were done for diphtheria toxin activites: Lobeck et al. (1998) combined two fragments of diphtheria toxin (DT), receptor binding domain and a linear peptide which fused at a tandem repeat of Ig binding domain of protein A called ZZ. They demonstrated that purified complex is well recognized by horse anti-DT antibodies and can bind to Vero cells. But they could not conclude that the complex hybrid constitutes can be an appropriate vaccine against diphtheria. Because first, it remains to be demonstrated that rabbits immunized. Second, their comparative analysis of antisera revealed that the commercial DTx elicits antisera with higher anti-DT titers and higher neutralizing potency compared to substance. Third, Protein A moiety can bind to rabbit IgGs, and the immunization with such a fusion protein may potentially elicit an anti-lgG immune response (Lobeck et al., 1998). Chiang et al. (as reported by Lee et al., 2004), investigated the expression and immunogenicity of a nontoxic DT fragment A (DTA) in $S$. gordonii, with the long-term goal of developing a live oral diphtheria pertussis- tetanus vaccine. They combined DTA with $S$. gordonii major surface antigen P1. The fusion proteins were immunogenic in mice, but the antibodies generated lacked neutralizing activity. The aim of this study was cloning and expression diphtheria toxin gene to produce recombinant protein, as powerful antigen in exciting immuno response, and application in next investigations.

\section{ACKNOWLEDGMENT}

This study was derivative of student thesis and supported by Cellular and Molecular Biology Research Center (CMBRC) of Shaheed Beheshti University of Medical Sciences.

\section{REFERENCES}

Aybay C, Yücel A (2003). Development of a diagnostic and screening ELISA system for measuring diphtheria anti-toxin levels. Turk. J. Med. Sci., 33: 289-294.

Bachran C, Sutherland M, Bachran D, Fuchs H (2007). Quantification of diphtheria toxin-mediated ADP-ribosylation in a solid-phase assay. Clin. Chem., 53(9): 1676-1683.

Baneyx F (1999). Recombinant protein expression in Escherichia coli. Curr. Opin. Biotechnol., 10:411-421.

Barbieri JT, Armellini D, Molkentin J, Rappuoli R (1992). Construction of a diphtheria toxin A fragment-C180 peptide fusion protein which elicits a neutralizing antibody response against diphtheria toxin and pertussis toxin. Infect. Immun., 60: 5071-5077.

Beachey EH, Seyer JM, Dale JB, Simpson WA, Kang A (1981). Type specific protective immunity evoked by synthetic peptide of Streptococcus pyogenes M protein. Nat., 292:457.

Bigio M, Rossi R, Nucci D, Antoni G, Rappuoli R, Ratti G (1987). Conformational changes in diphtheria toxoids. Analysis with monoclonal antibodies. FEBS Lett., 218: 271-276.

Brooks GF, Carroll CK, Butel JS, Morse AS (2007). Jawetz, Melnick \& Adelberg's Medical Microbiology, edited by G.F. Brooks,. $24^{\text {th }}$ edithtion: pp. $154-217$.

Collier RJ, Kandel J (1971). Structure and activity of diphtheria toxin. I. Thiol-dependent dissociation of a fraction of toxin into enzymatically active and inactive fragments. J. Biol. Chem., 246: 1496-1503.

DeLange RJ, Drazin RE, Collier RJ (1976). Amino-acid sequence of fragment $A$, an enzymatically active fragment from diphtheria toxin. 
Proc. Natl. Acad. Sci. U.S.A., 73: 69-72.

Diphtheria vaccination, Vaccines and preventable diseases: Centers for Disease Control and Prevention. http://www.cdc.gov/vaccines/vpdvac/diphtheria/default.htm

Drazin R, Kandel J, Collier RJ (1971). Structure and activity of diphtheria toxin. II. Attack by trypsin at a specific site within the intact molecule. J. Biol. Chem., 246: 1504-1510.

Feliciecello I, Chinali G (1993). A modified alkaline lysis method for the preparation of highly purified plasmid DNA from E. coli. Anal Biochem., 212(2): 394 - 401.

Fromen-Romano $C$, Maillère $B$, Drevet $P$, Lajeunesse $E$, Ducancel $F$, Boulain JC, Ménez A (1997). Transformation of a non-enzymatic toxin into a toxoid by genetic engineering. Protein Eng., 10: 101-108.

Gaastra W, Hansen K (1984). Ligation of DNA with T4 DNA ligase. In methods in Molecular Biology. Nucleic Acids. Ed, Walker JM. Humana Press., 2: 225-30.

Gill DM, Pappenheimer AM Jr (1971). Structure-activity relationships in diphtheria toxin. J. Biol. Chem., 246: 1492-1495.

Gill DM, Dinius LL (1971), Observations on the structure of diphtheria toxin. J. Biol. Chem., 246: 1485-1491.

Hanahan D (1983). Studies on transformation on E. coli with plasmids. J. Mol. Biol., 166(4): 557-580.

Holmes RK (2000). Biology and molecular epidemiology of diphtheria toxin and the tox gene. J. Infect. Dis., 181(SUPPL. 1): S156-67

Honjo T, Nishizuka Y, Hayaishi O (1968). Diphtheria toxin-dependent adenosine diphosphate ribosylation of aminoacyl transferase II and inhibition of protein synthesis by diphtheria toxin. J. Biol. Chem., 243: 3553-3555

Hudsun L, Hay FC (1998). Antibody interaction with antigen. In: Hudsun L, Hay FC. Practical Immunology. 3rd ed. Oxford; Boston: Blackwell Scientific Publication., $207-263$.

Ittelson TR, Gill DM (1973). Diphtheria toxin: specific competition for cell receptors. Nature (London), 242: 330-332.

Killeen KP, Escuyer V, Mekalanos JJ, Collier RJ (1992). Reversion of recombinant toxoids: Mutations in diphtheria toxin that partially compensate for active-site deletions. Proc. Nat. Acad. Sci. USA., 89(13): 6207-6209.

Lobeck K, Drevet $\mathrm{P}$, Léonetti M, Fromen-Romano C, Ducancel F, Lajeunesse E, Lemaire C, Ménez A (1998). Towards a recombinant vaccine against diphtheria toxin. Infect. Immunity., 66(2): 418-423.

Mandell GBJ, Dolin R (eds.) (1995). Mandell, Douglas, Bennett's Principles and Practice of Infectious Diseases. Churchill Livngstone, New York: 1865- 1872.
Mikhailovich VM, Melnikov VG, Mazurova IK, Wachsmuth IK, Wenger JD, Wharton M, Nakao H, Popovic T (1995). Application of PCR for detection of toxigenic $C$. diphtheriae strains isolated during the Russian diphtheria epidemic, 1990 through 1994. Clin. J. Microbiol., 33(11): 3061-3063.

Naglich JG, Metherall JE, Russell DW, Eidels L (1992). Expression cloning of a diphtheria toxin receptor: identity with a heparin-binding EGF-like growth factor precursor. Cell, 69(6): 1051-1061.

Nakao H, Popovic T (1997). Development of a direct PCR assay for detection of the diphtheria toxin gene. Clin. J. Microbiol., 35(7): 16511655.

Papini E, Rappuoli R, Murgia M, Montecucco C (1993). Cell penetration of diphtheria toxin. Reduction of the interchain disulfide bridge is the rate-limiting step of translocation in the cytosol. J. Biol. Chem., 268(3): 1567-1574

Sambrook J, Russell DW (2001). Molecular cloning. A laboratory manual, cold sapring harbor laboratory pres, third edition., 1,2,3.

Shewry PR, Fido RJ (1998). Protein blotting, Principles and Applications. In: Rapley R, Walker JM, eds. Molecular Biomethods Handbook. Totowa, NJ: Humana Press. pp. 435 - 444.

Skogen V, Jenum PA, Danilov E, Korolev VN, Halvorsen DS, Sjursen H (2000). Immunity to diphtheria among childern in Northen Norway and North- Western Russia. Vaccine, 19: 197-203.

Smith BJ (1984a). Acetic Acid-Urea Polyacrylamide Gel Electrophoresis of Proteins. In: Walker John, ed. Methods in Molecular Biology. Vol 1. Clifton: Humana Press, $63-73$.

Smith BJ (1984b). SDS polyacrylamide gel electrophoresis of proteins. In: Methods in Molecular Biology. Vol. 1. Proteins. Edited by John M Walker., Chap. 6: 41-56.

Sorensen H, Mortensen K (2005). Advanced genetic strategies for recombinant protein expression in Escherichia coli. J. Biotechnol., 115: 113-128.

Todar K (2008). Diphtheria. University of Wisconsin-Madison Department of Bacteriology, pp. 1-8.

Turosk V (1985). Formaldehyde: Analytical Chemistry and Toxicology; Advances in Chemistry. American Chemical Society,Washington DC.

Uchida T, Pappenheimer AM Jr, Greany R (1973). Diphtheria toxin and related proteins.I. Isolation and properties of mutant proteins serologically related to diphtheria toxin. J. Biol. Chem., 248: 38383844 . 